Open Access

\title{
Microcystin-LR regulates circadian clock and antioxidant gene expression in cultured rat cardiomyocytes
}

\author{
Yonghua $\mathrm{Xu}^{{ }^{1 \dagger}}$, Xiangmin Wang ${ }^{2 \dagger}$, Surong Jiang ${ }^{2}$, Chen $\mathrm{Men}^{2}$, Di Xu ${ }^{2}$, Yan Guo ${ }^{2}$ and Jun $\mathrm{Wu}^{2^{*}}$ (D)
}

\author{
* Correspondence: \\ wujun9989@njmu.edu.cn \\ ${ }^{\dagger}$ Yonghua $\mathrm{Xu}$ and Xiangmin Wang \\ contributed equally to this work. \\ 2Department of Geriatric \\ Cardiology, The First Affiliated \\ Hospital of Nanjing Medical \\ University, 300 Guangzhou Rd, \\ Nanjing 210029, China \\ Full list of author information is \\ available at the end of the article
}

\begin{abstract}
Background: Microcystins are waterborne environmental toxins that induce oxidative stress and cause injuries in the heart. On the other hand, many physiological processes, including antioxidant defense, are under precise control by the mammalian circadian clock.

Results: In the present study, we evaluated the effect of microcystin-LR (MC-LR) on the rhythmic expression patterns of circadian and antioxidant genes in rat cardiomyocytes using the serum shock technique. We found that a non-toxic dose $(10 \mu \mathrm{m})$ of MC-LR decreased the amplitudes of rhythmic patterns of clock genes, while it increased the expression levels of antioxidant genes.

Conclusions: Our results indicate an influence of MC-LR on the circadian clock system and clock-controlled antioxidant genes, which will shed some light on the explanation of heart toxicity induced by MC-LR from the viewpoint of chronobiology.
\end{abstract}

Keywords: Circadian clock, Antioxidant defense, Microcystin-LR, Heart

\section{Introduction}

A great number of physiological events in living organisms exhibit 24-h circadian rhythm fluctuations [1-3]. These intrinsic biological rhythms are driven by a circadian clock and are dominantly governed by light-dark (LD) and feeding cycles. The mammalian circadian clocks comprise a central clock and slave oscillators. The central clock is located in the hypothalamic suprachiasmatic nucleus (SCN), while slave oscillators are found in various tissues, which can be driven by the central clock via behavioral and neuroendocrine signals [4]. At the molecular level, autoregulatory transcriptional translational feedback loops involving several clock genes build up intracellular clocks. Nearly $43 \%$ of all genes are expressed in a circadian manner in the whole genome [5].

Microcystin (MC) is a kind of cyclic heptapeptide compound, which is the most ubiquitously distributed hepatotoxin. It is mainly produced by freshwater species of Microcystis. MCs were reported to cause illness or even death in animals and humans [6]. Mechanistically, MCs inhibit both protein serine/threonine phosphatases-1 and 2A $[7,8]$, enhance formation of reactive oxygen species (ROS) and interact with mitochondrial ATP synthase, aldehyde dehydrogenase and also with mitochondrial oxidative

(c) The Author(s). 2018 Open Access This article is distributed under the terms of the Creative Commons Attribution 4.0 International License (http://creativecommons.org/licenses/by/4.0/), which permits unrestricted use, distribution, and reproduction in any medium, provided you give appropriate credit to the original author(s) and the source, provide a link to the Creative Commons license, and indicate if changes were made. The Creative Commons Public Domain Dedication waiver (http://creativecommons.org/ publicdomain/zero/1.0/) applies to the data made available in this article, unless otherwise stated. 
phosphorylation [9, 10]. Microcystin-LR (MC-LR) is the most common and well-known toxic variant among the microcystin family [11]. Hepatocytes become apoptotic and necrotic when exposed to large doses of MC-LR. On the other hand, MC-LR contributes to the development of liver cancer and damages the heart under chronic poisoning.

When oxidative stress is induced by MCs, intracellular antioxidant defense is evoked, trying to remove its harmful consequences. Several key enzymes such as catalase, superoxide dismutase, and heme oxygenase play a vital role in this process. It is interesting that the levels of these antioxidant enzymes and low molecular weight antioxidants such as glutathione also show circadian rhythms, which leads to time dependence of the sensitivity to environmental oxidants $[12,13]$. Hence, we hypothesized that MC-LR may alter the rhythmic expression patterns of clock and antioxidant genes in the heart, which contributes to its myocardial toxic effects.

\section{Materials and methods}

\section{Ethical statement}

This article does not describe any studies with human participants or animals performed by any of the authors.

\section{Cell culture}

The H9C2 cardiomyocytes were grown in Dulbecco's modified essential medium (DMEM; high glucose; Gibco-Invitrogen, Carlsbad, USA), supplemented with 10\% (v/v) fetal bovine serum (FBS; Gibco-Invitrogen), $25 \mathrm{mmol} / \mathrm{L}$ HEPES ( $\mathrm{pH}$ 7.4), penicillin $(100 \mathrm{U} / \mathrm{mL})$, and streptomycin $(100 \mathrm{mg} / \mathrm{mL})$ at $37^{\circ} \mathrm{C}$ in a humidified atmosphere of $95 \%$ air and $5 \% \mathrm{CO}_{2}$.

\section{MTT assay}

The effect of MC-LR (Taiwan Algal Science, Taiwan) on H9C2 cell viability was analyzed by using an MTT assay. Cells were seeded in 96-well plates $\left(1 \times 10^{4}\right.$ cells per well). MC-LR $(0.1-100 \mu \mathrm{m})$ or vehicle $(0.0001-0.1 \%$ DMSO) was added to cells and incubated for $24 \mathrm{~h}$. After that, MTT $(0.2 \mathrm{mg} / \mathrm{ml})$ was added to each well and incubated for $4 \mathrm{~h}$. The supernatant was removed and the formazan crystals were dissolved in DMSO. Cell viability was assessed by measuring the absorbance at $550 \mathrm{~nm}$ using a microplate reader.

\section{Serum shock}

To assess the rhythmic gene expression in $\mathrm{H} 9 \mathrm{C} 2$ cells, serum shock experiments were performed (Balsalobre et al. 1998). In brief, medium was replaced with DMEM plus $50 \%$ horse serum $(t=0)$. After $2 \mathrm{~h}, \mathrm{H} 9 \mathrm{C} 2$ cells were washed once with PBS buffer and incubated with serum-free DMEM with or without $10 \mu \mathrm{M}$ MC-LR. Cells were collected at the indicated time-points and subjected to reverse transcription-quantitative PCR (RT-qPCR) analysis.

\section{RT-qPCR}

Total RNA from H9C2 cells was extracted using Trizol reagent (Invitrogen, Carlsbad, CA). $1 \mu \mathrm{g}$ of total RNA was reverse-transcribed into complementary DNA. A primer 
for rat $18 \mathrm{~s}$ rRNA was included for normalization. mRNA levels were quantified by real-time RT-PCR using SYBR premix Ex Taq (Takara, Japan). Samples were amplified using the Mastercycler ep realplex2 system (Eppendorf, Hamburg, Germany). Primer sequences are available upon request. The fold change value was calculated by applying the following equation: fold change $=2^{-(\Delta \Delta \mathrm{Ct})}$.

\section{Statistical analysis}

Groups of data are presented as mean \pm standard error. Data were analyzed using two-way ANOVA followed by Fisher's LSD post-hoc test. Calculations were performed using the statistical package SPSS for Windows version 12.5S (SPSS, Chicago, USA). A value of $P<0.05$ was considered statistically significant.

\section{Results}

We first investigated the toxicity of MC-LR towards rat H9C2 cardiomyocytes by measuring cell viability using the MTT test. As shown in Fig. 1, MC-LR was cytotoxic when the concentration was higher than $10 \mu \mathrm{m}$. Therefore, a $10 \mu \mathrm{m}$ dose of MC-LR was chosen for the following experiments because it was the highest dose that did not change cell viability significantly.

Next, we induced rhythmic expression of circadian clock and antioxidant genes in H9C2 cardiomyocytes by serum shock. To determine whether MC-LR would affect the expression of the clock and antioxidant genes, a $10 \mu \mathrm{m}$ dose of MC-LR was added to the medium and the cells were cultured until collection at the indicated times. As shown in Fig. 2, a significant diurnal oscillation for all the clock genes examined was observed (repeated measures ANOVA analysis, $P<0.05$ ), except for bmal1 and per1. bmal1 showed semidiurnal rather than diurnal rhythm, which may be due to the difference between the in vitro cell culture condition and the in vivo physiological condition. The perl gene did

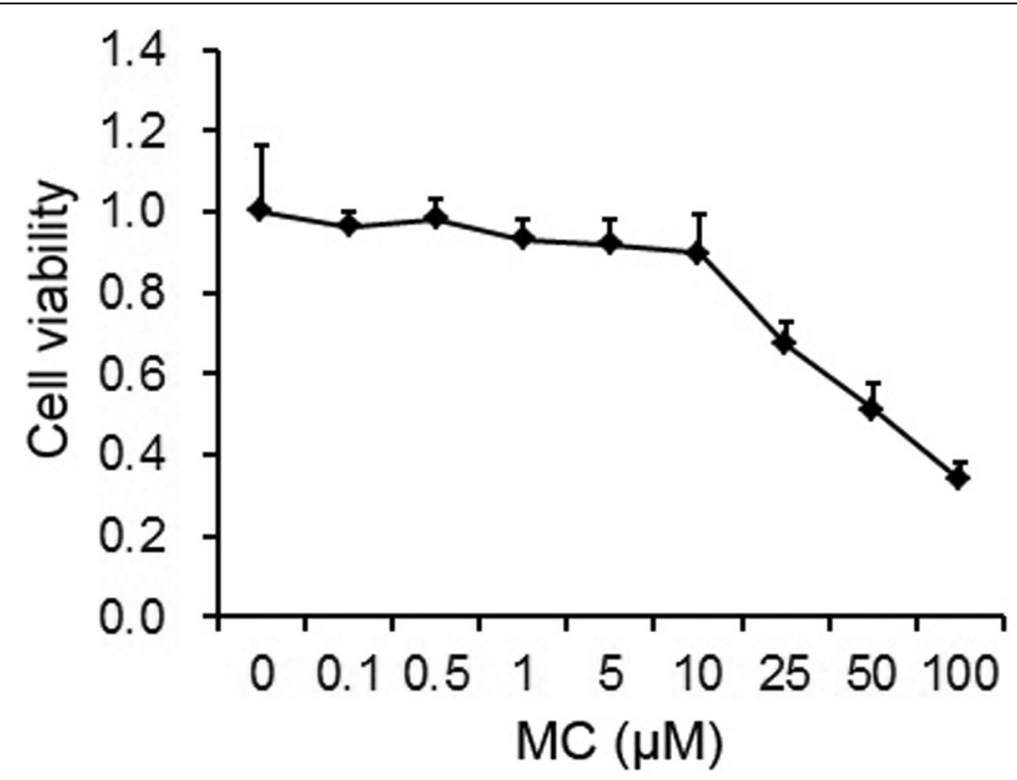

Fig. 1 Effects of MC-LR on H9C2 cell viability. H9C2 cells seeded in 96-well plates were treated with increasing concentrations of MC-LR for $24 \mathrm{~h}$ before the MTT assay 


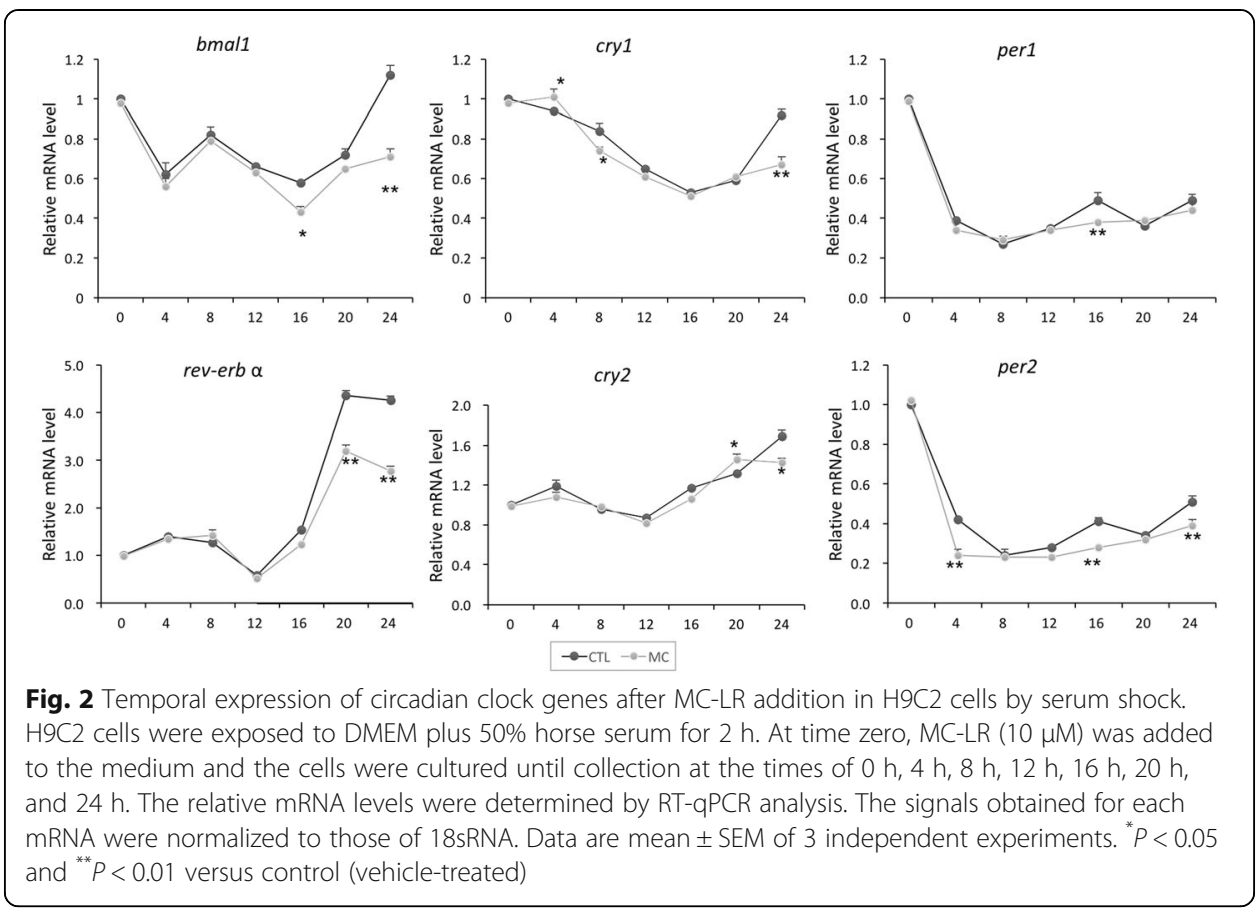

not display an obvious circadian oscillation, which is in line with previous findings [14]. Of note, all the genes shared a similar rhythmic expression pattern. Their mRNA levels were decreased in the first several hours, and then gradually increased. MC-LR treatment did not alter the phase of oscillation patterns of clock genes, but inhibited the amplitudes at most checked time-points. Such inhibitions became robust when the treatment lasted.

Since MC-LR can increase ROS formation, it is interesting to examine the changes of rhythmic expression of antioxidant genes when MC-LR treatment was present. As shown in Fig. 3, the mRNA expression levels of heme oxygenase-1 (ho-1) and catalase showed robust diurnal oscillations, while the expression of superoxide dismutase 1 ( $\operatorname{sod} 1)$ and $\operatorname{sod} 2$ remained constant during a $24 \mathrm{~h}$ period. On the other hand, MC-LR treatment significantly increased the expression levels of all examined antioxidant genes. Of note, the induction of sod2 by MC-LR reached the maximum levels at $8 \mathrm{~h}$ and $12 \mathrm{~h}$. However, MC-LR only moderately increased, or did not change, sod 2 expression at other examined time-points. Such time-dependent regulation seemed to make sod2 oscillate. Moreover, we analyzed the average 0-24 h rhythmic expression levels of clock and clock-controlled antioxidant genes separately via average bar graphs. As shown in Fig. 4, we found that MC-LR treatment slightly suppressed the clock genes, while it increased the expression of antioxidant genes.

\section{Discussion}

In this study, we found for the first time that MC-LR regulates clock and antioxidant genes in rat $\mathrm{H} 9 \mathrm{C} 2$ cardiomyocytes. The amplitude of rhythmic expression of clock genes was decreased by MC-LR. Similar phenotypes have been observed in various pathophysiological settings, such as aging, obesity, and cancer [15-17], implicating the 


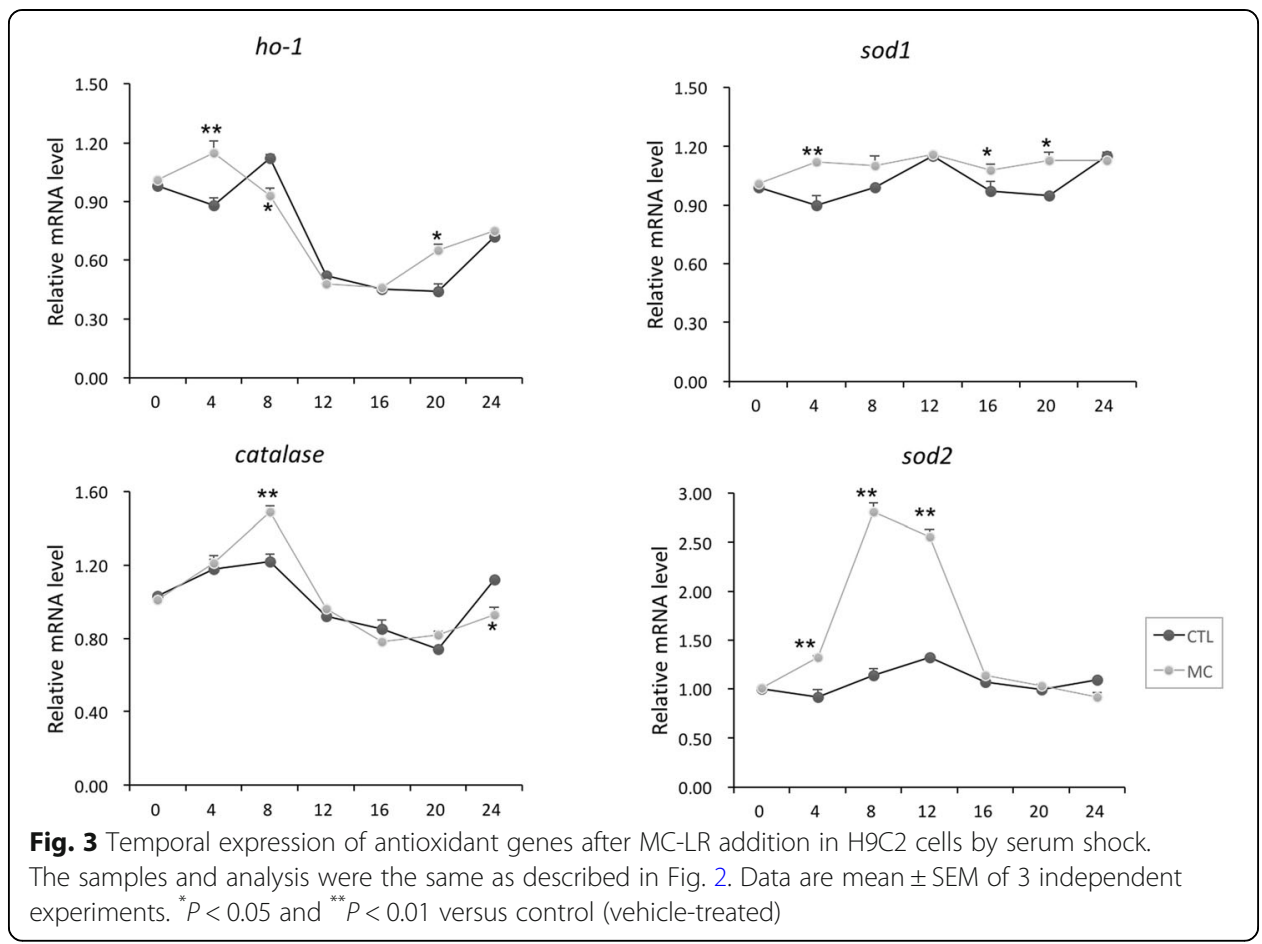

impairments of inner microenvironment homeostasis within cells. Our findings support this notion and provide evidence that MC-LR causes cellular toxicity by suppressing the robustness of the circadian clock.

The transcriptional control of genes involved in antioxidant defense and the oxidative stress response by the circadian clock can occur in several ways. Some antioxidant genes, such as GPX-1, Cat, Sod-1, and TXNRD-1, can be directly regulated by the circadian clock transcriptional factors BMAL1/CLOCK, RORs, and Rev-Erbs. They can also be regulated by clock-controlled transcriptional factors. Finally, regulation may occur through clock-dependent control of epigenetic modification by clock-controlled chromatin-modifying enzymes. [18, 19] As to the antioxidant genes, the expression levels of $\operatorname{sod} 1$ and $\operatorname{sod} 2$ were stable and did not oscillate. The constitutive expression of $\operatorname{sod} 1$ and $\operatorname{sod} 2$ in various tissues has been reported [20] and demonstrates the importance of these two enzymes in the cellular antioxidant defense. They are the main quenchers for superoxide, which is the most active and harmful species. On the other hand, all the examined antioxidant genes showed increased expression levels upon MC-LR treatment. We believe that

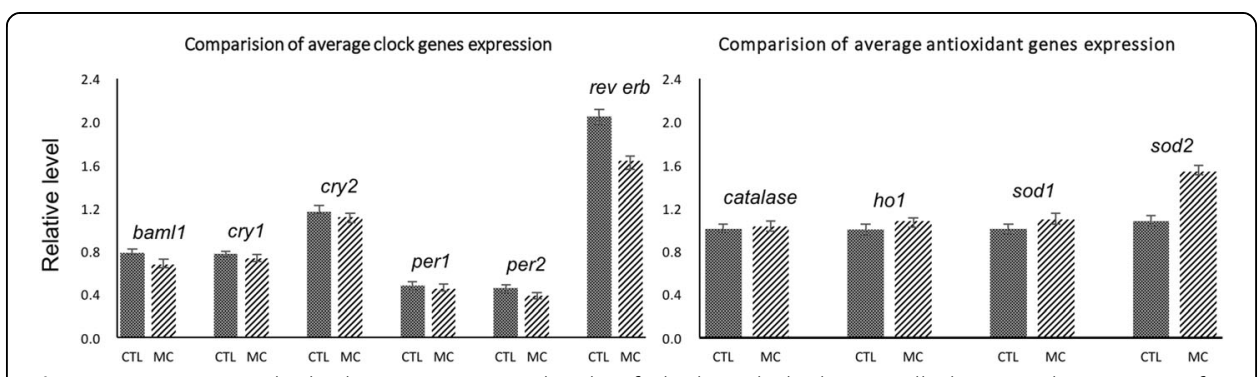

Fig. 4 Average $0-24 \mathrm{~h}$ rhythmic expression levels of clock and clock-controlled antioxidant genes after MC-LR addition in H9C2 cells by serum shock. Data are mean \pm SEM of 3 independent experiments 
this phenotype reflected the heavier burden of oxidative stress within cells, and therefore higher amounts of antioxidant enzymes were required to relieve more severe oxidative stress.

Although it is known that MC-LR impairs the heart function and alters the structure of heart muscle [21], the mechanism involved remains unclear. Recent studies have found that the homeostasis of the circadian clock and the function of the cardiovascular system are tightly integrated [22]. The results of our study indicate an influence of MC-LR on the circadian clock system and clock-controlled antioxidant genes, which will shed some light on the explanation of heart toxicity induced by MC-LR from the viewpoint of chronobiology.

\section{Conclusions}

Collectively, our results indicated that in addition to the previously reported toxicological effects, MC-LR also has a profound influence on modulation of the circadian clock system of cardiomyocytes. Therefore, the systemic toxicity of MC-LR may show a diurnal oscillation and should be re-evaluated from the viewpoint of chronobiology.

\section{Abbreviations}

bmal1: Brain and muscle Arnt-like protein-1; cry1: Cryptochromes 1; DMEM: Dulbecco's modified Eagle's medium; DMSO: Dimethyl sulfoxide; FBS: Fetal bovine serum; GPX-1: Glutathione peroxidase 1; ho-1: Heme oxygenase-1; LD: Light-dark; MC: Microcystin; MTT: 3-(4,5-dimethylthiazol-2-yl)-2,5-diphenyltetrazolium bromide; PBS: Phosphate buffered saline; per1: Period 1; RORs: Retinoic acid receptor-related orphan receptors; ROS: Reactive oxygen species; RTqPCR: Reverse transcription-quantitative polymerase chain reaction; SCN: Suprachiasmatic nucleus; sod-1: Superoxide dismutase 1; TXNRD-1: Thioredoxin reductase 1

\section{Funding}

This work was supported by the National Natural Science Foundation of China (Grant No. 81301616) and the Natural Science Foundation of Jiangsu Province (Grant No. BK20161057), and was also supported by Jiangsu Provincial Key Discipline of Medicine (ZDXKA2016003) and the Priority Academic Program Development of Jiangsu Higher Education Institutions (PAPD).

\section{Availability of data and materials}

The datasets used and/or analyzed during the current study are available from the corresponding author on reasonable request.

\section{Authors' contributions}

$Y X, D X$, and $Y G$ contributed to the conception and design of the research and interpreted the results of the experiments; $Y X$ and XW performed the experiments; CM and SJ analyzed the data; $Y X$ prepared the figures; JW drafted the manuscript; all authors read and approved the final manuscript.

Ethics approval and consent to participate

Not applicable.

Consent for publication

Not applicable.

Competing interests

The authors declare that they have no competing interests.

\section{Publisher's Note}

Springer Nature remains neutral with regard to jurisdictional claims in published maps and institutional affiliations.

Author details

${ }^{1}$ Department of General Surgery, The Fourth Affiliated Hospital of Nantong University, Yancheng 224006, China. ${ }^{2}$ Department of Geriatric Cardiology, The First Affiliated Hospital of Nanjing Medical University, 300 Guangzhou Rd, Nanjing 210029, China. 
Received: 27 June 2018 Accepted: 28 September 2018

Published online: 10 October 2018

\section{References}

1. King DP, Takahashi JS. Molecular genetics of circadian rhythms in mammals. Annu Rev Neurosci. 2000;23:713-42.

2. Rutter J, Reick M, McKnight SL. Metabolism and the control of circadian rhythms. Annu Rev Biochem. 2002;71:307-31.

3. Wijnen H, Young MW. Interplay of circadian clocks and metabolic rhythms. Annu Rev Genet. 2006;40:409-48.

4. Hastings M, Reddy A, Maywood E. A clockwork web: circadian timing in brain and periphery, in heath and disease. Nat Rev Neurosci. 2003;4:649-61.

5. Lowery P, Takahashi J. Mammalian circadian biology: elucidating genome-wide levels of temporal organization. Annu Rev Genomics Hum Genet. 2004;5:407-11.

6. Carmichael WW. The toxins of cyanobacteria. Sci Am. 1994;270:78-86.

7. Shuai Y, Lou D, Yin J, Qian X, Wang Y, Hong X, et al. Characterization of microcystin-induced dualistic toxic effects on primary rat hepatocytes. J Environ Pathol Toxicol Oncol. 2017;36:15-27.

8. Garda T, Kónya Z, Tándor I, Beyer D, Vasas G, Erdődi F, et al. Microcystin-LR induces mitotic spindle assembly disorders in Vicia faba by protein phosphatase inhibition and not reactive oxygen species induction. J Plant Physiol. 2016;199:1-11.

9. Ding W, Shen H, Ong C. Calpain activation after mitochondrial permeability transition in microcystin-induced cell death in rat hepatocytes. Biochem Biophys Res Commun. 2002;291:321-31.

10. Ding W, Ong C. Role of oxidative stress and mitochondrial changes in cyanobacteria-induced apoptosis and hepatotoxicity. FEMS Microbiol Lett. 2003;220:1-7.

11. Gupta N, Pant SC, Vijayaraghavan R, Rao PV. Comparative toxicity evaluation of cyanobacterial cyclic peptide toxin microcystin variants (LR, RR,YR) in mice. Toxicology. 2003;188:285-96.

12. Blanco RA, Ziegler TR, Carlson BA, Cheng PY, Park Y, Cotsonis GA, et al. Diurnal variation in glutathione and cysteine redox states in human plasma. Am J Clin Nutr. 2007:86:1016-23.

13. Xu YQ, Zhang D, Jin T, Cai DJ, Wu Q, Lu Y, et al. Diurnal variation of hepatic antioxidant gene expression in mice. PLoS One. 2012;7:e44237.

14. Morse D, Cermakian N, Brancorsini S, Parvinen M, Sassone-Corsi P. No circadian rhythms in testis: Period1 expression is clock independent and developmentally regulated in the mouse. Mol Endocrinol. 2003;17:141-51.

15. Chaudhari A, Gupta R, Makwana K, Kondratov R. Circadian clocks, diets and aging. Nutr Healthy Aging. 2017;4:101-12.

16. Sherman H, Genzer Y, Cohen R, Chapnik N, Madar Z, Froy O. Timed high-fat diet resets circadian metabolism and prevents obesity. FASEB J. 2012;26:3493-502.

17. Padmanabhan K, Billaud M. Desynchronization of circadian clocks in Cancer: a metabolic and epigenetic connection. Front Endocrinol (Lausanne). 2017;19(8):136.

18. Patel SA, Velingkaar NS, Kondratov RV. Transcriptional control of antioxidant defense by the circadian clock. Antioxid Redox Signal. 2014;20:2997-3006.

19. Kondratov RV, Vykhovanets O, Kondratova AA, Antoch MP. Antioxidant N-acetyl-L-cysteine ameliorates symptoms of premature aging associated with the deficiency of the circadian protein BMAL1. Aging (Albany NY). 2009;1:979-87.

20. Zelko IN, Mariani TJ, Folz RJ. Superoxide dismutase multigene family: a comparison of the CuZn-SOD (SOD1), Mn-SOD (SOD2), and EC-SOD (SOD3) gene structures, evolution, and expression. Free Radic Biol Med. 2002;33:337-49.

21. Milutinović A, Zorc-Pleskovic R, Petrovic D, Zorc M, Suput D. Microcystin-LR induces alterations in heart muscle. Folia Biol (Praha). 2006;52:116-8.

22. Kohsaka A, Waki H, Cui H, Gouraud SS, Maeda M. Integration of metabolic and cardiovascular diurnal rhythms by circadian clock. Endocr J. 2012;59:447-56.

- fast, convenient online submission

- thorough peer review by experienced researchers in your field

- rapid publication on acceptance

- support for research data, including large and complex data types

- gold Open Access which fosters wider collaboration and increased citations

- maximum visibility for your research: over $100 \mathrm{M}$ website views per year

At BMC, research is always in progress.

Learn more biomedcentral.com/submissions 